\title{
Ecological Health Assessment of Chinese National Parks Based on Landscape Pattern: A Case Study in Shennongjia National Park
}

\author{
Hang Shu ${ }^{1,2}$, Chunwang Xiao ${ }^{1,2}$, Ting Ma ${ }^{1,3,4}$ and Weiguo Sang ${ }^{1,2, *(D)}$ \\ 1 Key Laboratory of Ecology and Environment in Minority Areas (Minzu University of China), National Ethnic \\ Affairs Commission of China, Beijing 100081, China; sdshuhang@163.com (H.S.); cwxiao@muc.edu.cn (C.X.); \\ 17400198@muc.edu.cn (T.M.) \\ 2 College of Life and Environment Science, Minzu University of China, Beijing 100081, China \\ 3 Key Laboratory of Regional Sustainable Development Modeling, Chinese Academy of Sciences, \\ Beijing 100101, China \\ 4 Institute of Geographic Sciences and Natural Resources Research, Chinese Academy of Sciences, \\ Beijing 100101, China \\ * Correspondence: swg@muc.edu.cn
}

check for

updates

Citation: Shu, H.; Xiao, C.; Ma, T.; Sang, W. Ecological Health Assessment of Chinese National Parks Based on Landscape Pattern: A Case Study in Shennongjia National Park. Int. J. Environ. Res. Public Health 2021, 18, 11487. https://doi.org/ 10.3390/ijerph182111487

Academic Editors: Sungroul Kim, Judy S. LaKind and Ana Rule

Received: 3 September 2021

Accepted: 29 October 2021

Published: 31 October 2021

Publisher's Note: MDPI stays neutral with regard to jurisdictional claims in published maps and institutional affiliations.

Copyright: (c) 2021 by the authors. Licensee MDPI, Basel, Switzerland. This article is an open access article distributed under the terms and conditions of the Creative Commons Attribution (CC BY) license (https:// creativecommons.org/licenses/by/ $4.0 /)$.

\begin{abstract}
Assessing the health of the ecosystem based on the landscape pattern of national parks can facilitate policy makers in formulating more targeted conservation policies to better manage national park ecosystems. To analyze the landscape patterns and characteristics of the national park, the ecosystem health evaluation index system of the national park was constructed using the vigororganization-resilience (VOR) model to evaluate the health status. In this study, the Shennongjia National Park in China was selected as a case study area to be assessed using the index system. The results revealed that the patches of construction land and farmland are the largest in number and the most complex in shape, reflecting the obvious fragmentation of construction land and farmland patches. All patch types in this national park were evenly distributed. The results of the analysis showed that the comprehensive index of national park heath, according to the VOR model, is 0.74 , indicating that the ecosystems in this study area were in a good state of health. Ecosystems in strictly protected areas of this park had the highest ecosystem health index levels, while the traditional utilization areas had the lowest. Ecosystem health levels were characterized by significant spatial agglomeration characteristics, with high-high aggregation distribution areas, mainly clustered in strictly protected areas, and low-low aggregation distribution, mainly clustered in traditional utilization areas and marginal areas. This study provided a set of ecosystem health assessment systems and their practical use in China's newly established national parks.
\end{abstract}

Keywords: landscape pattern; ecosystem health; national park; spatial analysis; VOR model

\section{Introduction}

Maintaining the health of natural ecosystems at a high level can provide adequate and sustainable material support for the development of human society [1]. As a result of the continuous increase in human activity, a series of ecosystem health problems have followed, such as land desertion, habitats loss, greatly reduced forest coverage rate and so on [2]. These problems lead to unhealthy natural ecosystems, seriously hindering sustainable development. In this context, how to protect the health of natural ecosystems to promote sustainable development has not only become the focus of scholars, but has also become a high priority national strategy [3]. Quite a few countries have established various types of protected areas such as national parks to protect significant ecosystems [4,5].

In China, in order to protect the habitat of endangered and precious animals and plants and the integrity of the natural ecosystem, the first nature reserve was established in 1956 [6]. By 2020, China had established more than 11,800 natural protected areas of 
different levels and types [7]. However, nature reserves have a series of problems such as unclear boundaries, overlapping settings, and prominent contradictions in protection and development [8]. To address these problems, in 2017, China's government proposed a scheme of setting up a National Park System Pilot Area to better protect natural ecosystems and achieve sustainable development of natural ecosystems [9]. National parks are established to play a vital role in the national nature reserve system. The healthy ecosystem of national parks is conducive to protecting biodiversity and promoting human development [10]. A comprehensive assessment of national park ecosystem health is needed for the construction of high-quality national parks [11]. The aim of this study is to establish a set of methodologies for ecosystem health assessment in national parks in China.

Ecosystem health is considered to be one of the most important issues in ecosystem management, and it is also a key part of ecosystem assessment [12]. A healthy ecosystem should not only be self-active but should also be able to maintain and renew itself [13]. In recent years, there have been lots of related studies on ecosystem health assessment. The ecosystem health assessment involves different scales, which includes global scale, regional scale with administrative units, watershed scales, and specific ecoregional scales [14-17]. There are also some studies assessing the health status of different ecosystems, such as the aquatic ecosystems of coasts and rivers and the terrestrial ecosystems of agriculture and forests [18-21]. In terms of the assessment methodology, when considering the scale and characteristics of the study area, it is mainly divided into an indicator species method and an indicator system method. The indicator species method is an indirect method to assess the ecosystem health by monitoring and analyzing the response of representative indicator species to external environmental pressures [22]. The assessing process of this method is relatively complicated. The indicator system method is mainly used to assess the ecosystem health level by establishing the evaluation models [23]. At present, the commonly used evaluation models mainly include the vigor-organization-resilience (VOR) model and pressure-state-response (PSR) model [24]. The VOR assessment model emphasizes the integrity of ecosystem structure and function, including vitality, resilience and landscape pattern within the ecosystem, emphasizing the properties of the ecosystem itself [25]. The PSR assessment model mainly researched causal relationships between ecosystems and human activities, largely considering ecosystem pressure, state, and response [26].

As one of the most important types of protected natural areas in China, national parks are subject to the rigorous scientific protection [27]. Therefore, the ecosystem health of national parks is relatively slightly affected by human activities, and the properties of their own ecosystem status are key factors affecting the ecosystems health. At present, most of the ecosystem health studies of various natural protected areas mainly focus on the assessment of the temporal or the process changes of ecosystem health, and there is a lack of ecosystem health studies based on landscape pattern analysis [28]. Consequently, it is necessary to analyze the landscape pattern index to establish a suitable evaluation system to learn the landscape pattern characteristics and the ecosystem health status.

Shennongjia National Park, one of the first batch National Park System Pilot Areas in China, with the most typical evergreen deciduous broadleaf mixed forest ecosystem worldwide. This study area also has a variety of national key protected wild animals and plants such as Rhinopithecus roxellana, Davidia involucrata, Taxus wallichiana var. chinensis and so on, which are of global significance for biodiversity conservation $[29,30]$. It also has great ecological value, so it is of vital significance to protect its ecosystem health [11]. Until now, there have been no studies on ecosystem health assessment based on landscape pattern in Shennongjia National Park. Moreover, this study area has just been established in 2016, and a comprehensive and detailed study of its current ecosystem health is more meaningful for the development of the national park. Therefore, this study takes Shennongjia National Park as a case study and selects VOR model to establish the ecosystem health assessment system based on landscape pattern analysis. We used Fragstats software to explore the landscape pattern of the national park. Based on landscape pattern characteristics, the VOR model was used to study the ecosystem health level, and Arcgis software was used 
to assess the distribution features of ecosystem health level in Shennongiia National Park in China.

\section{Materials and Methods}

\subsection{Study Area}

Shennongjia National Park is located in Hubei Province of China, with geographic coordinates of $109^{\circ} 56^{\prime} \mathrm{E}-110^{\circ} 36^{\prime} \mathrm{E}$ and $31^{\circ} 17^{\prime} \mathrm{N}-31^{\circ} 36^{\prime} \mathrm{N}$ (Figure 1). It covers a total area of $1167 \mathrm{~km}^{2}$. It is located in the northern subtropical monsoon climate zone. The annual precipitation is between $800-2500 \mathrm{~mm}$. Shennongjia National Park has integrated a variety of protected areas in the past, such as national nature reserves, national forest parks and so on [31]. This area is rich in biodiversity and is recognized as one of the key areas for biodiversity conservation in the whole world [32]. According to the characteristics of this national park, there are four main functional divisions in it that have been established, including a strictly protected area, recreation display areas, ecological conservation areas and traditional utilization areas for better performing the natural conservation and socioeconomic functions of national parks [33].

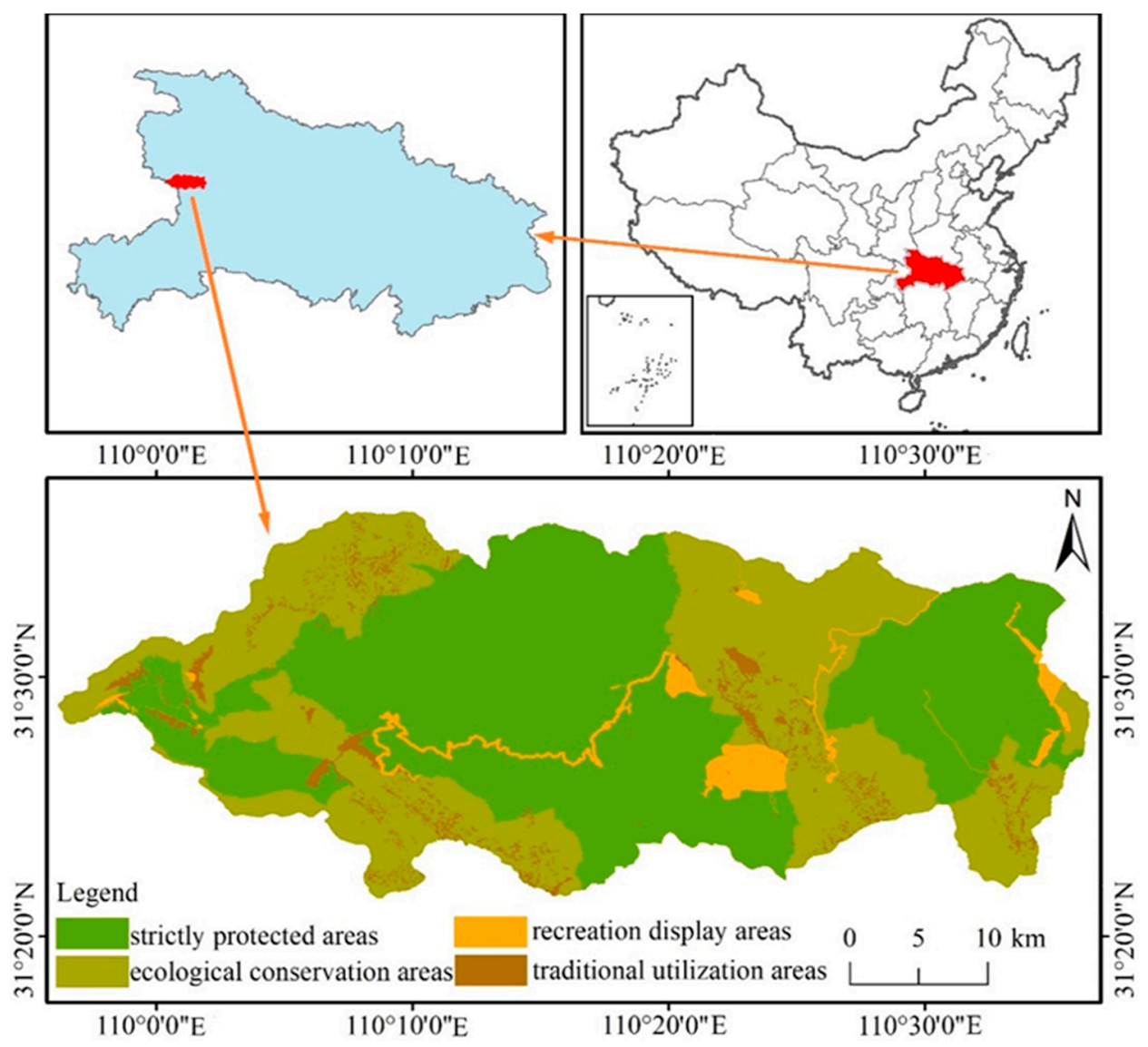

Figure 1. The location of Shennongjia National Park in China and its functional divisions.

\subsection{Data Collection and Analysis}

\subsubsection{Spatial Data Pre-Processing and Classification of Landscape Types}

In this study, the Landsat OLI remote sensing images with a resolution of $30 \mathrm{~m} \times 30 \mathrm{~m}$ in 2019 was selected as the basic data source. The detailed data parameters are shown in Table 1. These images were obtained from the United States Geological Survey website (http:/ / glovis.usgs.gov / (accessed on 16 September 2020)). Based on ENVI 5.3 software, the image is interpreted using the supervised classification method of maximum likelihood method. On the basis of supervised classification, combined with forest resource inventory data and Google Earth data, the images were visually corrected to improve the classification 
accuracy, so as to obtain land use data of Shennongiia National Park. According to the practical requirements, the land use data was classified into ten types: coniferous forest, deciduous broadleaf forest; evergreen broadleaf forest; mixed coniferous broadleaf forest; shrubs; grassland; construction land; farmland; water body and bare land. To ensure a reliable classification, kappa values were used to evaluate the accuracy. The kappa values are larger than 0.850 , which meets the application requirements of this study.

Table 1. The detailed data parameters of remote sensing images.

\begin{tabular}{cccccc}
\hline Date & Path & Row & Cloudcover & Sunelevation & Sunazimuth \\
\hline $2019 / 11 / 03$ & 125 & 38 & 2.87 & 40.36029328 & 157.45013021 \\
$2019 / 11 / 10$ & 126 & 38 & 5.44 & 38.36455604 & 158.26941673 \\
\hline
\end{tabular}

\subsubsection{Selection of Landscape Pattern Indexes}

Firstly, the land use classification map was rasterized and transformed into GRID TIFF format. Then, Fragstats 4.2 software was used to calculate the landscape pattern index of the study area from the class level and landscape level. Although there are many landscape pattern indexes that can be used for landscape pattern analysis, some of them have collinearity [34]. In order to avoid such issues and take regional characteristics into consideration, this study selected corresponding evaluation indexes at the class level and landscape level, respectively, to analyze the landscape pattern of Shennongjia National Park. The ecological significance of the landscape pattern indexes used are shown in Table 2.

Table 2. The ecological significance of the landscape pattern indexes.

\begin{tabular}{|c|c|}
\hline Index & Ecological Significance \\
\hline CA (Total class area) & The CA is the sum of the areas of all the patches in a landscape type. \\
\hline PLAND (Percentage of landscape) & $\begin{array}{c}\text { The PLAND is the total area of a landscape type as a percentage of the total area of } \\
\text { the study area. }\end{array}$ \\
\hline LPI (Largest patch index) & $\begin{array}{c}\text { The LPI is the proportion of the largest patch in a landscape type to the total area } \\
\text { of the study area. }\end{array}$ \\
\hline NP (Number of patches) & $\begin{array}{l}\text { The NP index refers to the total number of patches of a certain landscape type and } \\
\text { is usually used to describe the heterogeneity of the entire landscape. }\end{array}$ \\
\hline PD (Patch density) & $\begin{array}{c}\text { The PD index is an important indicator reflecting the degree of fragmentation and } \\
\text { dispersion of the landscape. }\end{array}$ \\
\hline LSI (Landscape shape index) & The LSI is an index which can reflect the characteristics of the patch shape. \\
\hline COHESION (Patch Cohesion Index) & $\begin{array}{l}\text { The COHESION index reflects the degree of natural connectivity of related } \\
\text { landscape types. }\end{array}$ \\
\hline CONTAG (Contagion Index) & $\begin{array}{c}\text { The CONTAG describes the degree of agglomeration or spreading trend of } \\
\text { different patch types in the landscape. }\end{array}$ \\
\hline IJI (Interspersion Juxtaposition Index) & $\begin{array}{l}\text { The IJI can reflect the overall interspersion and juxtaposition of various patch } \\
\text { types at the landscape level. }\end{array}$ \\
\hline SHEI (Shannon's Evenness Index) & $\begin{array}{l}\text { The SHEI is an indicator reflecting the dominant patches and their distribution } \\
\text { status in the landscape. }\end{array}$ \\
\hline SHDI (Simpson's Diversity Index) & $\begin{array}{l}\text { The SHDI index is sensitive to the uneven distribution of various patch types in } \\
\text { the landscape, and it emphasizes the contribution of rare patch types. }\end{array}$ \\
\hline
\end{tabular}

Note: Source: Previous research [35]. In this study, the indexes of CA, PLAND, LPI, NP, LSI were used for class level evaluation and the indexes of COHESION, CONTAG, IJI, SHEI, SHDI were used for landscape level evaluation.

\subsubsection{Selection of Grid Size and Landscape Pattern Indexes}

According to the ecosystem characteristics of Shennongjia National Park, the VOR model was used to establish the ecological health evaluation indicators. Firstly, the national park ecosystem health assessment was established as the objective layer. Then, according to the objective layer, three indicators of vigor, organization and resilience were established as the principal layer. Finally, nine representative indicator layers are selected from the 
principal layer. The indicators in the indicator layer constitutes the ecosystem health evaluation index system of national parks (Table 3).

Table 3. Ecosystem health evaluation indicator system of Shennongjia National Park.

\begin{tabular}{ccc}
\hline Objective Layer & Principle Layer & Quota Layer \\
\hline & Vigor & Vegetation Cover Index \\
\cline { 2 - 3 } & & COHESION (Patch Cohesion Index) \\
CoNTAG (Contagion Index) \\
Ecological health & & IJI (Interspersion Juxtaposition Index) \\
assessment of National & Organization & SHDI (Shannon's Diversity Index) \\
& & SHEI (Shannon's Evenness Index) \\
& & PR (Patch Richness) \\
\cline { 2 - 3 } & & SIDI (Simpson's Diversity Index) \\
& Resilience & Resilience Index \\
\hline
\end{tabular}

Note: The landscape pattern indexes in this table are based on the landscape level.

Acting as one of the most basic functions of the ecosystem, ecosystem vigor can be measured by metabolism or primary productivity [36]. In this study, the vegetation cover was applied to quantify ecosystem vigor, which is an important parameter for describing vegetation growth and ecosystem primary productivity [37]. Based on NDVI, the dimidiate pixel model was employed to calculate the vegetation coverage. The specific calculation method is as follows:

$$
F c=\frac{\mathrm{NDVI}-\mathrm{NDVI}_{\text {soil }}}{\mathrm{NDVI}_{\text {veg }}-\mathrm{NDVI}_{\text {soil }}}
$$

where, $\mathrm{NDVI}_{\text {soil }}$ represents the pixel NDVI value in the area without vegetation cover; $\mathrm{NDVI}_{\text {veg }}$ represents the pixel NDVI value with complete vegetation cover; $F c$ represents vegetation coverage, the values of $F c$ ranged from 0 to 1 .

Ecosystem organization is defined as the structural relationships among the components of an ecosystem, which mainly consists of landscape heterogeneity and landscape connectivity [38]. Landscape heterogeneity generally refers to the degree of landscape variation, which can reflect the difference in landscape types. Landscape heterogeneity was measured using Shannon's Diversity index (SHDI), Shannon's Evenness index (SHEI) and Patch Richness (PR) [39]. Landscape connectivity was quantified using the Patch Cohesion index (COHESION), Contagion index (CONTAG) and Interspersion Juxtaposition index (IJI) [40].

Ecosystem resilience is the key ability of an ecosystem to stably maintain its structure and function under environmental stresses from nature and society [41]. This study refers to the resilience coefficients of different land use types in previous related studies [12,41-44]. Different land use types have the specific reference resilience coefficients (Table 4). When calculating the resilience of the ecosystem, the resilience coefficient of coniferous forest, deciduous broadleaf forest, evergreen broadleaf forest, mixed coniferous broadleaf forest, shrubs are classified as resilience coefficient of forest land types. In addition, the richer the biodiversity in an ecosystem, the stronger the ability of the ecosystem to maintain its structure and function. Therefore, the Simpson Diversity index (SIDI) is also used as one of the indicators of ecosystem resilience.

Table 4. Ecosystem resilience coefficient of land use type.

\begin{tabular}{ccccccc}
\hline Ecosystem Type & Forest Land & Grassland & $\begin{array}{c}\text { Construction } \\
\text { Land }\end{array}$ & Farmland & Water Body & Bare Land \\
\hline Resilience coefficient & 0.9 & 0.8 & 0.2 & 0.5 & 0.8 & 0.2 \\
\hline
\end{tabular}


2.2.4. The Normalization of Evaluation Indicators and the Establishment of Indicator Weights

Normalization of evaluation indicators: When evaluating ecosystem health, the various types of indicators involved are not conducive to unified analysis and evaluation. Therefore, it is necessary to standardize each evaluation indicator and eliminate dimensions to complete the calculation between data [45]. In this study, the range method was used to standardize the data, and the value of the quota layer evaluation indicators were standardized to range from 0 to 1 .

When the increased direction of the single indicator value is the same as the increased direction of ecological health, Formula (2) is used for evaluation. Otherwise, Formula (3) is used for evaluation.

$$
\begin{aligned}
& P=\frac{R_{\max }-R}{R_{\max }-R_{\min }} \\
& P=\frac{R-R_{\min }}{R_{\max }-R_{\min }}
\end{aligned}
$$

where, $P$ represents the standardized single indicator value of ecological health; $R$ represents the observed value of a single indicator; $R_{\min }$ represents the minimum value of a single indicator; $R_{\max }$ represents the maximum value of a single indicator.

Weighting of ecosystem health indicators: In the ecosystem health evaluation system, the weight of indicators has an important impact on the evaluation results. The weights indicate the relative importance of the evaluation indicator to the previous one. A reasonable determination of the weight value can improve the accuracy and scientific validity of the evaluation results [46]. The Analytic Hierarchy Process (AHP) method was used in this study. Firstly, the hierarchical structure model which includes objective layer, principal layer and quota layer is constructed by yaahp software. Then, the hierarchical analysis method is used to compare and analyze the importance degree of the indicator under the principal layer $(P)$ and the quota layer $(Q)$, respectively to construct the judgment matrix. The matrix formula is as follows:

$$
P_{k}=\left(Q_{i j}\right)_{n \times n}=\left[\begin{array}{ccc}
Q_{11} & \cdots & Q_{1 n} \\
\vdots & \ddots & \vdots \\
Q_{n 1} & \cdots & Q_{n n}
\end{array}\right]
$$

Finally, the constructed judgment matrix will be tested for consistency of the matrix. The formulas are as follows:

$$
\begin{gathered}
C M=\frac{C I}{R I} \\
C I=\frac{\lambda_{\max }-n}{n-1}
\end{gathered}
$$

where, $C M$ represents the consistency of the matrix; $C I$ represents the consistency indicator; $R I$ represents the random consistent ratio; $\lambda_{\max }$ represents the maximum eigenvalue of the judgment matrix; $n$ represents the order of the matrix.

If the value of $C M<0.1$, it indicates that the judgment matrix satisfies the consistency. If the judgment matrix cannot satisfy the consistency, the initial value of the judgment matrix needs to be adjusted before performing the consistency check.

\subsubsection{Ecosystem Health Assessment Method and Assessment Grade Determination}

According to the weight of each indicator and the standardized single indicator value which was obtained by the above calculation, the ecosystem health value of the national park is obtained by weighted summation. The calculation formula is as follows:

$$
E=\sum_{i=1}^{n} S_{i} A_{i}
$$


where, $E$ is the national park ecosystem health index of the study area; $n$ is the number of indicators; $S_{i}$ is the standardized single indicator evaluation value; $A_{i}$ is the weight of corresponding indicator.

This study established the national park ecosystem health assessment criteria by comprehensively considering the actual situation of the national park and the previous evaluation criteria. The national park ecosystem health evaluation standard is divided into 5 grades using an equal-interval approach, which are represented by a continuous real number intervals $[0.00,1.00]$. The ecosystem health assessment value approach to 1 , the better the ecosystem health is. Conversely, the assessment value approach to 0 , the worse the health of the ecosystem is [47]. The following grades were used for the national park ecosystem health index: high-quality health $(0.80,1.00]$; good health $(0.60,0.80]$; health $(0.40,0.60]$; sub-health $(0.20,0.40]$; bad health $[0.00,0.20]$.

\subsubsection{Spatial Autocorrelation Analysis}

This study is based on the exploratory spatial autocorrelation analysis method to investigate the spatial dependence and agglomeration pattern of ecosystem health level in Shennongjia National Park. Exploratory spatial autocorrelation analysis method includes global spatial correlation and local spatial correlation. It can indicate the degree of interdependence and agglomeration between attributes in a specific area and attributes in other areas. Moran's I index was used to analyze the global spatial agglomeration of the entire study area, Formula (5) is used for calculation [48]. The local Moran's I (LISA) was used to analyze the spatial correlation between the spatial attribute value and its adjacent spatial attribute value, Formula (6) is used for calculation [49]. In the calculation process, permutation tests (999 permutations) were used for evaluating the statistical significance of the Moran's I. Additionally, in order to obtain credible spatial correlation analysis results, the statistical significance value at the $1 \%$ level was set.

The Getis-Ord Genral G analysis was used to further explore the characteristics of the agglomeration effects of the ecosystem health level. It can indicate the degree of agglomeration of high and low values. In this calculation process, we set the statistical significance value at the $1 \%$ level:

$$
\begin{gathered}
\text { Moran/s I }=\frac{\sum_{i=1}^{n} \sum_{j=1}^{m} w_{i j}\left(x_{i}-\bar{x}\right)\left(x_{j}-\bar{x}\right)}{S^{2} \sum_{i=1}^{n} \sum_{j=1}^{m} w_{i j}} \\
\text { Local Moran/s } I=\frac{n\left(x_{i}-\bar{x}\right) \sum_{j=1}^{m} w_{i j}\left(x_{j}-\bar{x}\right)}{\sum_{i=1}^{n}\left(x_{i}-\bar{x}\right)^{2}} \\
G=\frac{\sum_{i=1}^{n} \sum_{j=1}^{m} w_{i j} x_{i} x_{j}}{\sum_{i=1}^{n} \sum_{j=1}^{m} x_{i} x_{j}}
\end{gathered}
$$

where $n$ is the total of spatial units in Shennongjia National Park; $m$ is the number of spatial units geographically adjacent to spatial unit $j ; i \neq j, S=1 / n \sum_{i=1}^{n}\left(x_{i}-x\right)^{2} ; x_{i}, x_{j}$ represent the ecosystem health value of spatial units $i$ and $j ; w_{i j}$ represents the spatial weight matrix of units $i$ and $j ; x$ represents the average ecosystem health value. The values of $I$ ranged from -1 to 1 , and higher absolute values of $I$ reflect stronger spatial autocorrelations. There is a positive spatial correlation when $I>0$, a negative spatial correlation when $I<0$, and no spatial autocorrelation when $I=0$. There are four types of local autocorrelation: high-high $(\mathrm{HH})$, low-low (LL), high-low (HL), and low-high (LH), which represent the aggregation of spatial units with high ecosystem health levels, the aggregation of spatial units with low ecosystem health levels, and a spatial unit with a high (or low) ecosystem health value surrounded by spatial units with low (or high) ecosystem health values, respectively. 


\section{Results}

\subsection{Landscape Pattern Characteristics of Class Level}

According to the analysis of landscape pattern indexes of CA (total class area), PLAND (percentage of landscape) and LPI, the basic landscape pattern distribution characteristics of different landscape types were obtained (Table 5). Based on the indicators of CA and PLAND, we can obtain the composition of different plaque types in the study area. The indexes of PLAND and the LPI are important bases for determining landscape dominance in the region. It can be found that the main landscape types in the study area are deciduous broadleaf forest, shrubs, coniferous forest and mixed evergreen and deciduous broadleaf forest. These four landscape types account for up to $84.29 \%$, of which deciduous broadleaf forest account for the proportion is the highest at $43.99 \%$. The area of construction land follows the above four types, accounting for $8.46 \%$. The area of grassland, bare land, water body and bare land is very small, and the total area of these four types are merely less than 3\%. The order of the PLAND index value and the LPI index value of each landscape type is about the same, while the LPI index value of construction land is relatively large. Combining the index values of the CA, PLAND and LPI, it can be seen that deciduous broadleaf forests, shrubs and coniferous forests occupy a dominant position in Shennongjia National Park, and deciduous broadleaf forests play a major role in maintaining the patch integrity of the national park.

Table 5. Landscape pattern distribution characteristics of different landscape types.

\begin{tabular}{ccccccc}
\hline Landscape Types & CA (ha) & PLAND (\%) & LPI (\%) & NP (no.) & PD (no./100 ha) & LSI \\
\hline Coniferous forest & $15,094.08$ & 12.9579 & 5.2406 & 18 & 0.0155 & 8.5720 \\
Deciduous broadleaf forest & $51,441.59$ & 43.9896 & 22.1622 & 49 & 0.0421 & 0.0215 \\
Evergreen broadleaf forest & 5113.26 & 4.3896 & 1.1755 & 25 & 0.394 \\
Mixed coniferous broadleaf & $12,047.49$ & 10.3425 & 1.4362 & 25 & 0.0215 & 8.0369 \\
forest & $19,802.61$ & 17.0000 & 5.9547 & 26 & 0.0223 & 10.2151 \\
Shrubs & 2692.98 & 2.3119 & 0.3527 & 51 & 0.0438 & 10.9682 \\
Grassland & 475.83 & 0.4085 & 0.1080 & 525 & 0.4507 & 20.5479 \\
Farmland & 166.41 & 0.1429 & 0.0677 & 25 & 0.0215 & 6.9302 \\
Water body & 9851.22 & 8.4570 & 2.6256 & 676 & 0.5803 & 17.9154 \\
Construction land & 0.18 & 0.0002 & 0.0002 & 1 & 0.0009 & 1.0000 \\
Bare land & & & & &
\end{tabular}

In order to further analyze the landscape fragmentation characteristics of different landscape types in Shennongjia National Park, this study analyzed the indexes of NP, PD and LSI at the class level (Table 3). The largest number of patches (NP) are construction land (676) and farmland (525), accounting for $84.52 \%$ of the total number of patches. The number of patches of the above two types of land use is significantly higher than the number of patches of other landscape types. The PD index of construction land (0.58) and cultivated land (0.45) is also significantly higher than other landscape types. From the values of the NP index and PD index, it can be seen that the fragmentation of construction land and cultivated land are obvious. The LSI index of farmland and construction land is relatively high, which shows that the patch shape of farmland and construction land is more complicated. The LSI index value of the bare land and water body is low, which indicates that the patch shape of the bare land and water body is more regular.

\subsection{Landscape Pattern Characteristics of Landscape Level}

Because the ecosystem health assessment is based on the landscape pattern, the indexes of COHESION (Patch Cohesion Index), CONTAG (Contagion Index), IJI (Interspersion Juxtaposition Index), SHEI (Shannon's Evenness Index) and SHDI (Simpson's Diversity Index) were selected to analyze Shennongjia National Park's landscape pattern at landscape level (Table 6). 
Table 6. Landscape pattern characteristics index of the national park.

\begin{tabular}{ccccc}
\hline COHESION & CONTAG & IJI & SHEI & SHDI \\
\hline 99.5035 & 61.5169 & 73.0325 & 0.7066 & 1.6270 \\
\hline
\end{tabular}

The indicators of COHESION, CONTAG and IJI were used to characterize landscape connectivity. The results showed that the index value of COHESION is 99.5035, indicating that the landscape connection degree of the study area is relatively high. The results show that the CONTAG index value is 61.5169 , which indicated that the degree of agglomeration of different patch types in the study area belongs to superior middling level. The value of IJI index is 73.0325, which shows that the adjacent sides of the patches are relatively close. These indicators together illustrated that the landscape connectivity of Shennongiia National Park is relatively high.

The indicators of SHEI and SHDI were usually used to characterize the heterogeneity of the landscape. The SHEI index value of the study area is 0.7066 , which indicated that there are unobvious dominant patches in the landscape and the patch distribution is relatively uniform. The SHDI index value of the study area was 1.627 , which indicates that the uneven distribution of each patch type in the landscape is not obvious. The SHDI index together with the results of the SHEI index showed that the distribution of patches is relatively uniform.

\subsection{Comprehensive Assessment of Ecosystem Health in Shennongjia National Park}

Based on the analysis of the landscape pattern of Shennongjia National Park, the size of the scale with $1 \mathrm{~km} \times 1 \mathrm{~km}$ grid is used to assess the ecosystem health. According to the indicators and their weights in the VOR model, the ecosystem health of this national park is comprehensively assessed (Table 7).

Table 7. Comprehensive evaluation of Shennongjia National Park ecological health.

\begin{tabular}{ccccc}
\hline Evaluation Criteria & Evaluation Index & Weight & $\begin{array}{c}\text { Standardized } \\
\text { Indicator Value }\end{array}$ & $\begin{array}{c}\text { Comprehensive } \\
\text { Assessment Value }\end{array}$ \\
\hline Vigor (0.279) & Vegetation Cover Index & 0.297 & 0.989 & 0.74 \\
\hline & COHESION (Patch Cohesion Index) & 0.116 & 0.896 \\
Organization (0.541) & CONTAG (Contagion Index) & 0.116 & 0.497 \\
& IJI (Interspersion Juxtaposition Index) & 0.039 & 0.407 \\
& SHDI (Shannon's Diversity Index) & 0.070 & 0.399 \\
& SHEI (Shannon's Evenness Index) & 0.028 & 0.463 \\
Resilience (0.163) & PR (Patch Richness) & 0.172 & 0.526 \\
\hline \multirow{2}{*}{ SIDI (Simpson's Diversity Index) } & 0.027 & 0.458 \\
\hline
\end{tabular}

The average value of ecosystem health in Shennongiia National Park is 0.74 , which indicates that the ecosystem is a good level of health. From the grid level, the ecosystem health of each grid in this study area is at a healthy level and above the healthy level, and $26.38 \%$ grids are in high-quality health, $69.05 \%$ grids are in good health, $4.57 \%$ grids are in a health state (Figure 2).

Then, we overlay the distribution map of the ecosystem health level and the functional divisions to get the ecosystem health levels of strictly protected areas (SPA), ecological conservation areas (ECA), traditional use areas (TUA) and recreational exhibition areas (RDA) (Figure 3). SPA have the highest value of the ecosystem health index, with the average score is 0.78 , the highest score in the area is 0.94 , and the lowest score is 0.53 ; the ecosystem health index value of the RDA is second, with the average score is 0.77 , and the highest score in the area is 0.94 , the lowest score is 0.45 ; the average score of ecosystem health in the ECA is 0.73 , the highest score is 0.91 , the lowest score is 0.47 ; the ecosystem 
health index value of the TUA is the lowest, with the average score is 0.72 , the highest score is 0.91 , the lowest score is 0.42 .

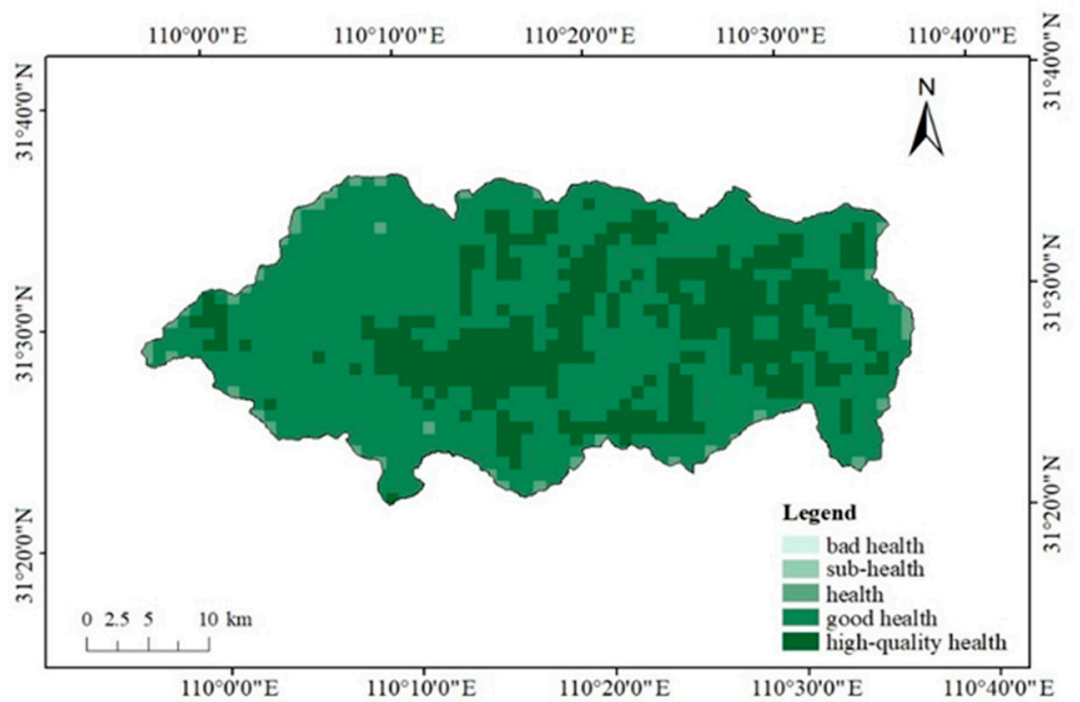

Figure 2. Ecosystem health level in Shennongiia National Park.

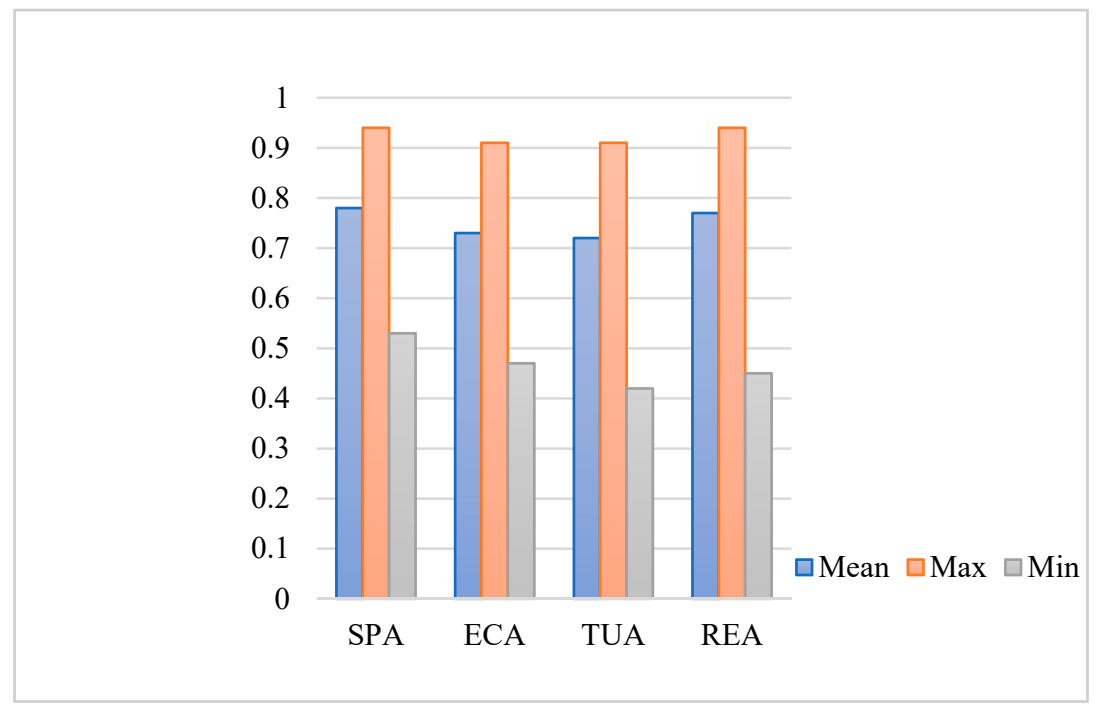

Figure 3. Ecosystem health level in functional divisions of Shennongiia National Park. (SPA, ECA, TUA and RDA are abbreviations of Strictly Protected Areas, Ecological Conservation Areas, Traditional Use Areas and Recreational Exhibition Areas, respectively).

\subsection{Spatial Pattern Characteristics of Ecosystem Health in Shennongiia National Park}

The overall spatial pattern characteristics of the ecosystem health level in Shennongjia National Park are analyzed by the global Moran's I index. The results show that the Moran's $I$ index value is 0.6110 with the $z$-score 30.08 ( $>2.58$ ), which was significant at the $1 \%$ level. The results implied that the ecosystem health level has a significantly positive spatial autocorrelation in this study area. In summary, the grids with similar ecosystem health levels had remarkable spatial agglomeration effects. Additionally, the analysis results of Getis-Ord General G showed that the observation value of General $G$ is 0.00784 with the z-score 18.25 (>2.58), which was significant at the $1 \%$ level. The expected value of General G is 0.00776 . The observed value is larger than the expected value. The results indicated that the high-high aggregation distribution is more than the low-low aggregation distribution.

The high-high and low-low types of spatial agglomeration of ecosystem health level were analyzed by the local Moran's I index (Figure 4). It can be concluded from the 
figure that the high-high aggregation distribution areas are mainly concentrated on strictly protected areas of the Shennongjia National Park. The number of grids with high-high type spatial agglomeration accounts for $18.00 \%$ of the total number of grids. The low-low aggregation distribution areas are mainly concentrated on traditional utilization areas and edge areas. The number of grids in the low-low type spatial agglomeration accounts for $11.09 \%$ of the total number of grids. The number of grids with the insignificant areas account for $70.36 \%$. Through overlay analysis, we found that the high-high type spatial agglomeration areas were mainly concentrated in the strict protection area, while the low-low aggregation distribution areas had no obvious distribution characteristics in the different functional divisions. Additionally, the low-low aggregation distribution areas were mainly distributed in the marginal areas.

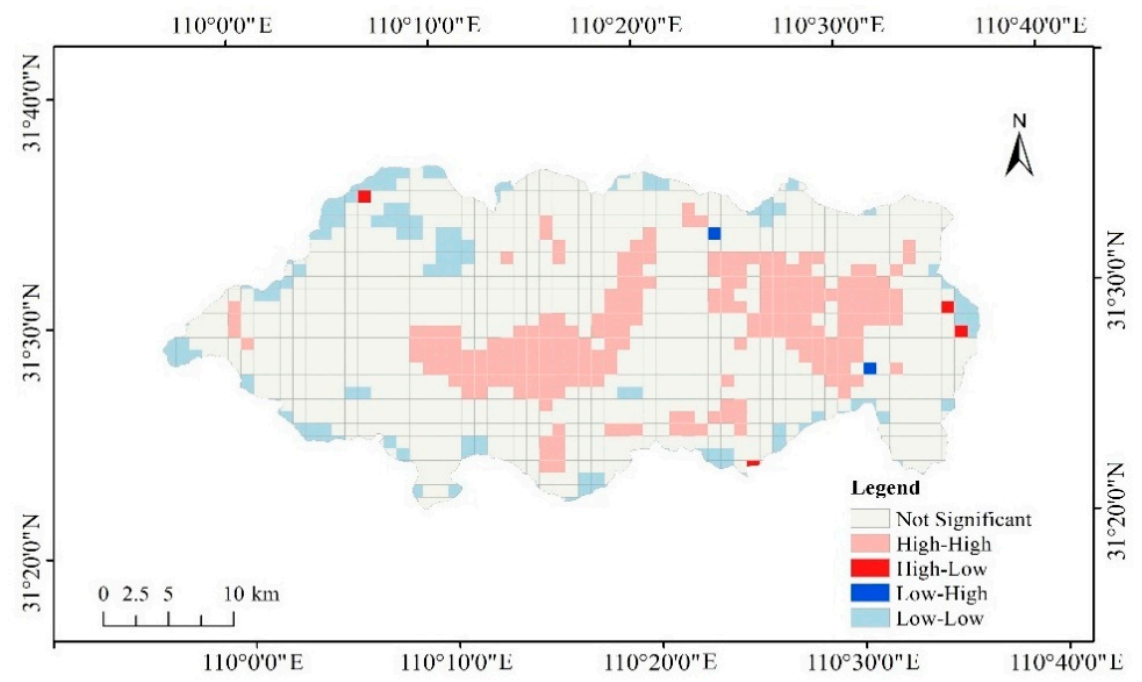

Figure 4. The spatial agglomeration of ecosystem health index in Shennongiia National Park.

\section{Discussion}

\subsection{Relationship between Landscape Pattern and Ecosystem Health}

Chinese government has established National Park System Plot Area based on its own national natural system conditions. The purpose is to protect the integrity of one or more typical ecosystems and provide places for eco-tourism, scientific research and environmental education, and those designated for special protection, management and utilization Natural area [50]. The establishment of Shennongjia National Park can effectively protect the integrity of the forest ecosystem in the region.

The number of patches of construction land is the largest, and distribution is relatively scattered. This may be due to the fact that the national park has carried out some infrastructure construction to realize the functions for eco-tourism, scientific research and environmental education in the past [51]. In addition, because of the infrastructure, construction must be built according to actual needs and geographical conditions. This resulted in a relatively scattered distribution of construction land in the national park. The patch shape of the farmland in Shennongiia National Park is the most complex, and the number of patches is followed secondly by the construction land. There are indigenous people who live in the national park. For their livelihood, they need a certain amount of farmland to ensure their daily demands and economic income [52]. Therefore, in order to better protect the ecological system health of the national park, some useful measures should be taken. For example, before building the infrastructure construction, we should make full multi-dimensional assessments of the ecological protection and sustainable development to optimize the quantitative structure and spatial patterns of construction land [53]. In addition, the indigenous people in national parks can increase the diversity of income sources such as planting some under-forest products with the policy permission and using 
local ecological resources to develop a green economy. In short, the supervisors can make the ecosystem at an optimal health status through reasonable and scientific landscape planning based on the characteristics of the landscape pattern and the results of the ecosystem health evaluation.

\subsection{Analysis of Ecosystem Health Status}

The ecosystem health condition of Shennongjia National Park is at a good health level, mainly because, before establishing it, the National Nature Reserve, National Forest Park, World Natural Heritage Site, National Geological Park as well as Dajiuhu National Wetland Park existed in this study area [31]. This means that the ecosystem in this area is well protected and has a high level of ecosystem health. In addition, the vegetation coverage in this study area is high, and the main vegetation type is forest. Among all landscape types studied, forest is the landscape type with the highest resilience index [40]. This is another reason for the high level of ecosystem health in this study area. The ecosystem health level in Shennongiia National Park had a significant spatial aggregation effect, which was related to the high landscape connectivity in the park. In addition, the closer the distance, the more obvious the interregional interaction, which led to the aggregation effect of ecosystem health. This phenomenon is similar to the Bayanbulak World Natural Heritage Site [17]. The high-high aggregation distribution areas are mainly concentrated in strict protected areas, which are often under strict control and protection so that high-high aggregation distribution areas are mainly concentrated here with a high level of ecosystem health. The low-low aggregation distribution was mainly concentrated in the marginal area, which, to a certain extent, reflects the protective effect of the establishment of national parks on the ecosystem. Thus, a certain area outside the marginal area is designated as a buffer zone to improve the health level of the marginal area.

\subsection{Implications for Ecological Conservation in Chinese National Park}

This research can provide useful suggestions for the development of differentiated ecological protection and restoration measures in the construction of national parks. In regional ecological protection and different areas should take different ecological protection measures [54]. In general, fragile ecological areas should be given priority [55]. Our research has identified regional differences in the ecosystem health level of Shennongjia National Park. The ecosystem health level of traditional utilization areas and marginal areas is relatively low. According to the landscape pattern analysis, the fragmentation degree of construction land and farmland in the traditional utilization areas is high, which may be the main reason for the low level of ecosystem health in this area. Therefore, landscape pattern planning should be strengthened in traditional utilization areas to improve the efficiency of ecological protection.

Regional ecosystem health assessment is not only important for scientific research, but also has good reference significance for policy formulation and implementation [56,57]. The construction of the Chinese National Park System Plot Area started after 2016. A detailed and comprehensive assessment of the current landscape pattern and ecosystem health status of national parks is of more guiding significance for the development of national parks. The assessment result can also provide reference methods and data for future multi-year ecosystem health assessments of Shennongjia National Park. In addition, the ecosystem health assessment method based on landscape pattern analysis established in this study can also be used to assess other national parks.

\subsection{Limitations and Future Research Directions}

This study introduces landscape patterns for the first time to assess the ecosystem health of national parks, which can greatly improve the efficiency of national park ecosystem health assessments. However, this study also has certain limitations.

The weight of each indicator in the VOR model is very important for ecosystem health assessment, and it will directly affect the assessment results [58]. In this study, 
although the AHP method was used to establish the indicators weight, there were still a certain degree of subjectivity. Therefore, when evaluating the ecosystem health level of national parks, the actual situation of national parks should be fully considered, and corresponding adjustments should be evaluated in multiple directions. Furthermore, the assessment criteria for ecosystem health level with the equal-interval approach has certain deficiencies, which should be based on a large number of practical studies to establish a unified standard. These should be the direction of future efforts. In this study, we evaluated the ecosystem health level of national parks based on the classic VOR model. This model focuses on the characteristics of the ecosystem, but it lacks consideration of the internal biological components of the natural ecosystem and the geographical environment factors. Therefore, the framework still needs to be studied and improved in detail in the future. In addition, we should continue to explore the driving factors and influencing mechanisms of ecological health. These will provide a scientific basis for policy makers and implementors to establish the suitable protection measures. Finally, in future research, we can also explore the relationship between the ecological health of national parks and human health to raise people's awareness of the protection of national parks, so as to promote the healthy development of national parks.

\section{Conclusions}

This study highlights the importance of the ecosystem health assessment approach based on the landscape pattern characteristic of exploring the ecosystem health status in Shennongjia National Park. The main research conclusions are as follows: (1) forest land is a dominant landscape type of Shennongiia National Park; (2) the landscape connectivity of the whole study area is relatively high; (3) the ecosystem health level of Shennongjia National Park is at a good health. Additionally, strictly protected areas have the highest level of ecosystem health, while traditional utilization areas have the lowest. (4) The ecosystem health level has a significantly positive spatial autocorrelation in Shennongjia National Park.

In general, this research analyzed the characteristics of the landscape pattern of Shennongiia National Park, which can provide a guidance for its landscape pattern planning. Through the analysis of the ecological system health level and distribution pattern characteristics of this national park, we have a comprehensive understanding of its ecological health status. The Shennongjia National Park priority reserve proposed in this study can provide a reference to help national park managers formulate more refined protection plans. In addition, this study established one ecosystem health assessment framework of a national park based on a landscape pattern, which can also be applied to other related national parks to improve management efficiency.

Author Contributions: Writing draft, H.S.; Data curation, H.S.; writing—review and editing, W.S. and C.X.; methodology, H.S. and T.M.; Supervision, W.S. All authors have read and agreed to the published version of the manuscript.

Funding: This research was supported by the Key Laboratory of Ecology and Environment in Minority Areas (Minzu University of China) National Ethnic Affairs Commission (Grant No. KLEEMA202105) and Ministry of Science and Technology of the People's Republic of China (Grant No. 2017YFC0506502).

Institutional Review Board Statement: Not applicable.

Informed Consent Statement: Not applicable.

Acknowledgments: We thank the scientists from Chinese Academy of Forestry, who friendly provided the related data. We are very grateful to the researchers of Shennongjia National Park Administration for their data support and help in field surveys. Thanks to Y.S.; G.L. and Y.X. for their help in the research method and data processing. We sincerely acknowledge the constructive comments of anonymous reviewers.

Conflicts of Interest: The authors declare no conflict of interest. 


\section{References}

1. Daily, G.C.; Alexander, S.; Ehrlich, P.R.; Goulder, L.; Tilman, D. Ecosystem services: Benefits supplied to human societies by natural ecosystems. Issues Ecol. 1997, 1, 1-16.

2. Wang, H.; Zhou, S.; Li, X.; Liu, H.; Chi, D.; Xu, K. The influence of climate change and human activities on ecosystem service value. Ecol. Eng. 2016, 87, 224-239. [CrossRef]

3. Xu, W.H.; Xiao, Y.; Zhang, J.J.; Yang, W.; Zhang, L.; Hullc, V.; Wang, Z.; Zheng, H.; Liu, J.G.; Liu, J.G.; et al. Strengthening protected areas for biodiversity and ecosystem services in China. Proc. Natl. Acad. Sci. USA 2017, 114, 1601-1606. [CrossRef]

4. Mallarach, J.M.; Verschuuren, B. Changing Concepts and Values in Natural Heritage Conservation: A View through IUCN and UNESCO Policies; The Getty Conservation Institute Press: Los Angeles, CA, USA, 2019; pp. 141-157. ISBN 978-16-0606-618-8.

5. Urbis, A.; Ramūnas, P.; Imanauskien, R.; Taminskas, J. Key aesthetic appeal concepts of coastal dunes and forests on the example of the Curonian Spit (Lithuania). Water 2019, 11, 1193. [CrossRef]

6. Ouyang, Z.Y. Development and status of forestry nature reserves in China. For. Sci. Technol. 2002, 4, 71-78.

7. Du, A.; Cui, T.; Ouyang, Z.Y. International experiences of national park selection criteria and the inspiration to China. Acta Geogr. Sin. 2020, 40, 7231-7237.

8. He, S.Y.; Su, Y.; Wang, L.; Louise, G.; Cheng, H.G. Taking an ecosystem services approach for a new national park system in China. Resour. Conserv. Recycl. 2018, 137, 136-144. [CrossRef]

9. Wang, J. National parks in China: Parks for people or for the nation? Land Use Policy 2019, 81, 825-833. [CrossRef]

10. Du, A.; Xu, W.; Xiao, Y.; Cui, T.; Ouyang, Z.Y. Evaluation of prioritized natural landscape conservation areas for national park planning in China. Sustainability 2020, 12, 1840. [CrossRef]

11. Wang, H.; Hou, P.; Jiang, J.B.; Xiao, R.L.; Zhai, J.; Fu, Z.; Hou, J. Ecosystem Health Assessment of Shennongjia National Park, China. Sustainability 2020, 12, 7672. [CrossRef]

12. Peng, J.; Liu, Y.X.; Wu, J.S.; Lv, H.L.; Hu, X.X. Linking ecosystem services and landscape patterns to assess urban ecosystem health: A case study in Shenzhen City, China. Landsc. Urban Plan. 2015, 143, 56-68. [CrossRef]

13. Rapport, D.J. What constitutes ecosystem health? Perspect. Biol. Med. 1989, 33, 120-132. [CrossRef]

14. Halpern, B.S.; Longo, C.; Hardy, D.; McLeod, K.L.; Samhouri, J.F.; Katona, S.K.; Kleisner, K.; Lester, S.E.; O’Leary, J.; Ranelletti, M.; et al. An index to assess the health and benefits of the global ocean. Nature 2012, 488, 615-620. [CrossRef]

15. Shi, Y.; Han, R.; Guo, L. Temporal-spatial distribution of ecosystem health and its response to human interference based on different terrain gradients: A case study in Gannan, China. Sustainability 2020, 12, 1773. [CrossRef]

16. Zhu, G.; Noman, M.A.; Narale, D.D.; Feng, W.; Sun, J. Evaluation of ecosystem health and potential human health hazards in the Hangzhou Bay and Qiantang Estuary region through multiple assessment approaches. Environ. Pollut. 2020, $264,114791$. [CrossRef]

17. Wang, Z.; Yang, Z.; Shi, H.; Han, F.; Liu, Y. Ecosystem health assessment of world natural heritage sites based on remote sensing and field sampling verification: Bayanbulak as case study. Sustainability 2020, 12, 2610. [CrossRef]

18. Kim, Y.O.; Xu, F.L. Marine ecosystem health assessments in Korean coastal water body. Ocean Sci. J. 2014, 49, 249-250. [CrossRef]

19. Pinto, U.; Maheshwari, B.L. River health assessment in peri-urban landscapes: An application of multivariate analysis to identify the key variables. Water Res. 2011, 45, 3915-3924. [CrossRef] [PubMed]

20. Wang, X.B.; Liu, W.N.; Wu, W.L. A holistic approach to the development of sustainable agriculture: Application of the ecosystem health model. Int. J. Sustain. Dev. World Ecol. 2009, 16, 339-345. [CrossRef]

21. Xiao, F.J.; Ouyang, H.; Fu, B.J.; Niu, H.S. Forest ecosystem health assessment indicators and application in China. Acta Geogr. Sin. 2003, 160, 805-809.

22. Pelletier, M.C.; Gold, R.J.; Heltshe, R.F.; Buffum, R.W. A method to identify estuarine macroinvertebrate pollution indicator species in the Virginian Biogeographic Province. Ecol. Indic. 2010, 10, 1037-1048. [CrossRef]

23. Kong, H.M.; Zhao, J.Z.; Ma, K.M.; Zhang, P.; Ji, L.Z.; Deng, H.B.; Lu, Z.H. Preliminary study on the evaluation method of ecosystem health. J. Appl. Ecol. 2002, 4, 486-490.

24. Cairns, J.; McCormick, P.V.; Niederlehner, B.R. A proposed framework for developing indicators of ecosystem health. Hydrobiologia 1992, 263, 1-44. [CrossRef]

25. Patil, G.P.; Brooks, R.P.; Myers, W.L.; Rapport, D.J.; Taillie, C. Ecosystem health and its measurement at landscape scale: Toward the next generation of quantitative assessments. Ecosyst. Health 2010, 7, 307-316. [CrossRef]

26. Das, S.; Pradhan, B.; Shit, P.K.; Alamri, A.M. Assessment of wetland ecosystem health using the pressure-state-response (PSR) model: A case study of mursidabad district of West Bengal (India). Sustainability 2020, 12, 5932. [CrossRef]

27. Wu, R.D.; Hua, C.L.; Yu, G.Z.; Ma, J.Z.; Yang, F.L.; Wang, J.J.; Jin, T.; Long, Y.C.; Guo, Y.; Zhao, H.W. Assessing protected area overlaps and performance to attain China's new national park system. Biol. Conserv. 2020, 241, 108382. [CrossRef]

28. Backhaus, R.; Bock, M.; Weiers, S. The spatial dimension of landscape sustainability. Environ. Dev. Sustain. 2002, 4, $237-251$. [CrossRef]

29. Zhang, Y.; Zhou, Y.Y.; Liu, X.F.; Yu, H.L.; Li, D.Q.; Zhang, Y.G. Genetic diversity of the sichuan snub-nosed monkey (rhinopithecus roxellana) in shennongiia national park, china using rad-seq analyses. Genetica 2019, 147, 327-335. [CrossRef]

30. Xie, D.; Wang, Y.Q.; Zhang, X.S.; Wu, Y.; Yang, J.Y.; Zhang, D.G. A catalogue of plant type specimens and history of plant collecting in Shennongjia National Park. Biodivers. Sci. 2019, 27, 211-218. 
31. Pan, S.L.; Wang, X.Q.; Mao, Y.; Wang, K.; Yu, Y. An analysis of the awareness and attitudes of community residents and visitors to national parks-Taking Shennongjia National Park as an example. Environ. Prot. 2019, 47, 65-69.

32. Chen, Y.; Guo, Y.; Liu, Y.; Chen, X.G.; Shao, C.Y. Detection and analysis of land cover changes in Shennongjia National Park from 1990 to 2016. For. Sci. Technol. News 2018, 1, 19-23.

33. Hubei Daily. Regulations on the Protection of Shennongjia National Park. Hubei Daily, 30 November $2017 ; 10$.

34. Turner, M.G.; Gardner, R.H. Landscape Ecology in Theory and Practice: Pattern and Process; Springer: New York, NY, USA, 2015; pp. 97-142. ISBN 978-1-4939-2794-4.

35. McGarigal, K.; Cushman, S.A.; Ene, E. FRAGSTATS v4: Spatial Pattern Analysis Program for Categorical Maps. Computer Software Program Produced by the Authors at the University of Massachusetts, Amherst, MA, USA. 2012. Available online: www.umass.edu/landeco/research/fragstats/fragstats.html (accessed on 1 June 2012).

36. Rapport, D.J.; Costanza, R.; Mcmichael, A.J. Assessing ecosystem health. Trends Ecol. Evol. 1998, 10, 397-402. [CrossRef]

37. Hou, W.; Gao, J.; Wu, S. Interannual variations in growing-season NDVI and its correlation with climate variables in the southwestern Karst region of China. Remote Sens. 2015, 7, 11105-11124. [CrossRef]

38. Liu, D.; Hao, S. Ecosystem health assessment at county-scale using the pressure-state-response framework on the Loess Plateau, China. Int. J. Environ. Res. Public Health 2017, 14, 2. [CrossRef] [PubMed]

39. Fan, L.; Li, Z. A model of ecosystem health and its application. Ecol. Model. 2003, 170, 55-59.

40. Xiao, Y.; Guo, L.; Sang, W.G. Impact of fast urbanization on ecosystem health in mountainous regions of southwest China. Int. J. Environ. Res. Public Health 2020, 17, 826. [CrossRef]

41. Turner, M.G. Landscape ecology: The effect of pattern on process. Annu. Rev. Ecol. Syst. 1989, 20, 171-197. [CrossRef]

42. Suo, A.; Xiong, Y.; Wang, T.; Yue, D.; Ge, J. Ecosystem health assessment of the Jinghe River watershed on the Huangtu Plateau. EcoHealth 2008, 5, 127-136. [CrossRef]

43. Peng, J.; Liu, Y.; Li, T.; Wu, J. Regional ecosystem health response to rural land use change: A case study in Lijiang City, China. Ecol. Indic. 2017, 72, 399-410. [CrossRef]

44. Xie, G.D.; Zhen, L.; Lu, C.X.; Xiao, Y.; Chen, C. Expert knowledge based valuation method of ecosystem services in China. J. Nat. Resour. 2008, 23, 911-919.

45. Richardson, A.D.; Keenan, T.F.; Migliavacca, M.; Ryu, Y.; Sonnentag, O.; Toomey, M. Climate change, phenology, and phenological control of vegetation feedbacks to the climate system. Agric. For. Meteorol. 2013, 169, 156-173. [CrossRef]

46. Sun, B.D.; Tang, J.C.; Yu, D.; Song, Z.W.; Wang, P.G. Ecosystem health assessment: A PSR analysis combining AHP and FCE methods for Jiaozhou Bay, China. Ocean Coast. Manag. 2019, 168, 41-50. [CrossRef]

47. Cheng, X.; Chen, L.D.; Sun, R.H.; Kong, P.R. Land use changes and socio-economic development strongly deteriorate river ecosystem health in one of the largest basins in China. Sci. Total Environ. 2018, 616-617, 376-385. [CrossRef]

48. Moran, P.A.P. Notes on continuous stochastic phenomena. Biometrika 1950, 37, 17-23. [CrossRef] [PubMed]

49. Anselin, L. Local indicators of spatial association-LISA. Geogr. Anal. 1995, 27, 93-115. [CrossRef]

50. Teng, M.J.; Zeng, L.X.; Zhou, Z.X.; Wang, P.C.; Xiao, W.F. Responses of landscape metrics to altering grain size in the Three Gorges Reservoir landscape in China. Environ Earth Sci. 2016, 75, 1055. [CrossRef]

51. Meng, W.A.; Li, S. Analysis on the construction path of Shennongjia National Park System Pilot Area. Int. J. Geoheritage Parks 2020, 8, 235-238.

52. Wang, Z.Z.; Mao, X.Q.; Zeng, W.H.; Xie, Y.X.; Ma, B.R. Exploring the influencing paths of natives' conservation behavior and policy incentives in protected areas: Evidence from China. Sci. Total Environ. 2020, 744, 140728. [CrossRef]

53. Frondoni, R.; Mollo, B.; Capotorti, G. A landscape analysis of land cover change in the Municipality of Rome (Italy): Spatiotemporal characteristics and ecological implications of land cover transitions from 1954 to 2001. Landsc. Urban Plan. 2011, 100, 117-128. [CrossRef]

54. Su, M.; Fath, B.D.; Yang, Z. Urban ecosystem health assessment: A review. Sci. Total Environ. 2010, 408, 2425-2434. [CrossRef]

55. Shen, W.; Zheng, Z.; Qin, Y.; Li, Y. Spatiotemporal characteristics and driving force of ecosystem health in an important ecological function region in China. Int. J. Environ. Res. Public Health 2020, 17, 5075. [CrossRef] [PubMed]

56. Rapport, D.J. Ecosystem services and management options as blanket indicators of ecosystem health. J. Aquat. Ecosyste Health 1995, 4, 97-105. [CrossRef]

57. Kang, P.; Chen, W.; Hou, Y.; Li, Y. Linking ecosystem services and ecosystem health to ecological risk assessment: A case study of the Beijing-Tianjin-Hebei urban agglomeration. Sci. Total Environ. 2018, 636, 1442-1454. [CrossRef] [PubMed]

58. He, J.H.; Pan, Z.Z.; Liu, D.F.; Guo, X.N. Exploring the regional differences of ecosystem health and its driving factors in China. Sci. Total Environ. 2019, 673, 553-564. [CrossRef] [PubMed] 